\title{
Percutaneous device closure of ventricular septal defect post-acute myocardial infarction and severe heart failure: possible alternative to surgery in selected cases or just a bridge to surgery?
}

\section{Comunicación interventricular postinfarto de miocardio agudo y falla cardiaca grave tratada mediante cierre percutáneo con dispositivo: ¿es una alternativa posible a la cirugía en casos seleccionados, o solo un puente a la intervención?}

\author{
Iván Melgarejo ${ }^{\mathrm{a}, \mathrm{b}, *}$, Darío Andrade $^{c}$, Ricardo Gomez Palau ${ }^{c}$, Roberto Lang ${ }^{c}$ \\ a Department of Noninvasive Cardiology, Cardiocolombia, Fundacion Abood Shaio, Bogotá, Colombia \\ b Department of Cardiovascular Surgery, Fundacion Abood Shaio, Bogotá, Colombia \\ ' Department of Noninasive Cardiac Imaging, University of Chicago Medical Center, USA
}

\section{KEYWORDS}

Percutaneous Device Closure;

Severe Heart Failure

\section{PALABRAS CLAVE}

Comunicación interventricular postinfarto;

Falla cardiaca

\footnotetext{
* Corresponding author.

E-mail addresses: ivanmelg@gmail.com, ivanmelg@yahoo.com (I. Melgarejo).
}

A 77 year-old woman with STEMI, who underwent thrombolysis and coronary angiography, severe three-vessel coronary artery disease and clinical features of heart failure. The surgery was postponed. At six weeks a trans-thoracic echocardiography (TTE) showed a ventricular septal defect (VSD). She was referred to our Institution. The patient was in severe cardiogenic shock, requiring inotropic support and mechanical assistance. A RT3D transesophageal echocardiogram (TEE) showed a VSD (Fig A) and severe shunt by color Doppler. Schematic figure of the VSD $(E)$. The decision was made to proceed with percutaneous closure of VSD. An occluder device was placed guided by TEE (Fig C), which confirmed adequate positioning with minimal residual shunt (Fig D).

The clinical course of the patient was initially good, but a week ago she deteriorated. TEE showed a significant leakage (Fig F). The patient was taken to emergency surgery. Inspection of the occluder device showed extension of the VSD at the inferior and superior border (Fig G). The VSD was closed with a Dacron single patch (Fig HD). The clinical course was excellent. 


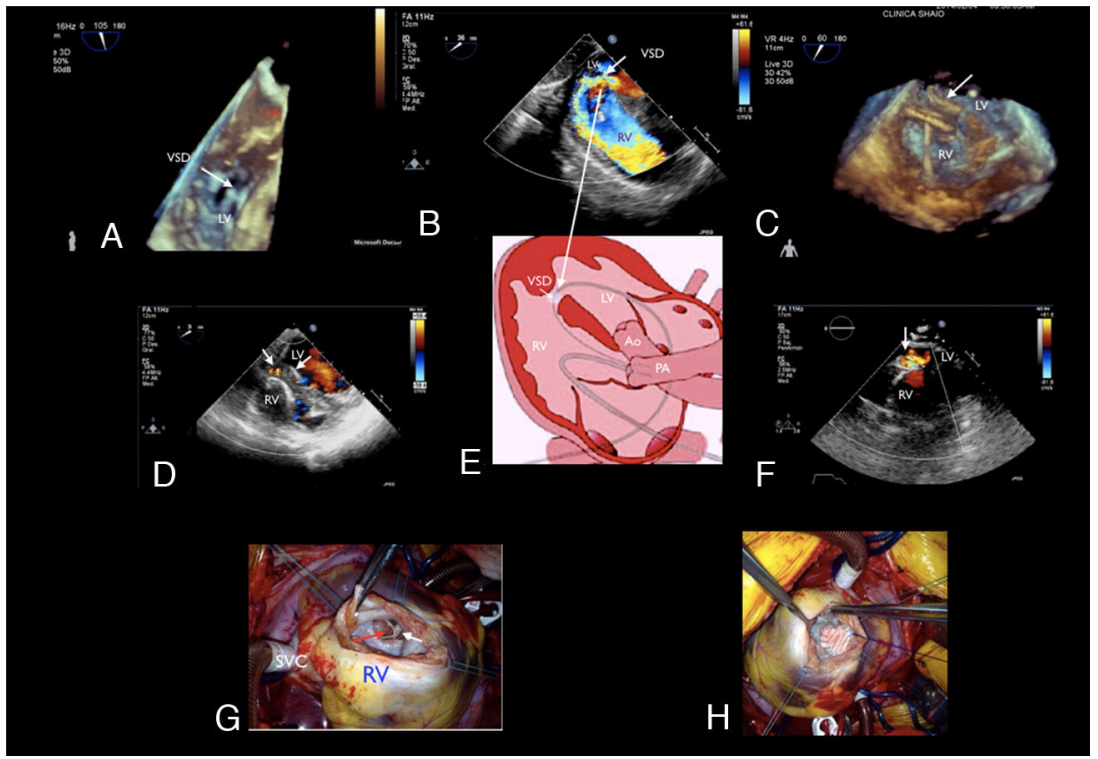

Figure 1 